Associates of North Alabama (RANA) is a large, communitybased rheumatology practice that treats approximately 6,000 patients with RA.

Objectives To document the experience with commercial infliximab in patients with RA treated in a community rheumatology practice.

Methods In an ongoing chart review of all patients receiving infliximab at RANA, the following information was documented: age, concomitant medication use, tender and swollen joint counts, and adverse side effects.

Results Baseline information was collected for 137 patients with RA. These patients ranged in age from 33 to 84 yrs (mean of $62.7 \mathrm{yrs}$ ). Among the 114 patients receiving concomitant methotrexate (MTX), doses ranged from 2.5 to $30 \mathrm{mg} /$ day (mean of $17.2 \mathrm{mg} /$ day). At baseline (prior to the first infliximab dose), the mean dose of prednisone was $6.2 \mathrm{mg} / \mathrm{day}$, and the mean tender and swollen joint counts were 22.4 and 13.7, respectively. Patients were treated with the currently recommended dosing regimen of $3 \mathrm{mg} / \mathrm{kg}$ at Weeks 0,2 , and 6 followed by q $8 \mathrm{wk}$ dosing. Forty $(29 \%)$ patients received concomitant disease-modifying antirheumatic drugs (DMARDs); 15 of these patients received concomitant leflunomide (12 with and 3 without MTX). Nine patients received infliximab without a concomitant DMARD. Data were available for 74 of these patients at Week 14 (fourth infliximab infusion). At this time point, the mean prednisone dose was $5.1 \mathrm{mg} / \mathrm{day}$, and mean tender and swollen joint counts had improved by $65 \%$ and $69 \%$ (to 7.8 and 4.3 ), respectively. Improvements in steroid use and tender and swollen joint counts also were observed at Week $30(n=42$; mean prednisone dose of $2.9 \mathrm{mg} /$ day and tender/swollen joint counts of 4.4/ 1.7) and Week $54(\mathrm{n}=14$; mean prednisone dose of $2.1 \mathrm{mg} /$ day and tender/swollen joint counts of 1.6/0.8) among the patients who had received treatment this long. Ten patients discontinued the use of infliximab due to lack of response (3 patients), rash (3 patients), cost (2 patients), abdominal pain (1 patient), and an unrelated side effect (neck pain in 1 patient). Five patients experienced infections (shingles, soft tissue abscess, pneumonia, and bronchitis in 2 patients); all patients responded to antibiotic therapy and continued treatment with infliximab.

Conclusion In a community rheumatology practice, infliximab 3 $\mathrm{mg} / \mathrm{kg}$, both with and without MTX, produced compelling improvement in the signs and symptoms of RA. Infliximab was safe and well tolerated when administered in the outpatient infusion setting.

\section{FRI0056 TNFALPHA THERAPY INITIATION AUDIT: RATIONING ON AN EQUITABLE BASIS - THE NORFOLK AND NORWICH (N/N) EXPERIENCE}

MF Somenille, A Price-Forbes, A Brooksby, J Leeder, JK Gaffney, P Merry, DG Scott. Rheumatology, Norfolk and Norwich University Hospital NHS Trust, Norwich, UK

\subsection{6/annrheumdis-2001.1185}

Background $\mathrm{BSR}^{1}$ and EULAR ${ }^{2}$ consensus guidelines have been published regarding the evolving use of TNF@ therapy in rheumatoid arthritis (RA). It is anticipated that demand will exceed supply. Norfolk Health Authority has allocated $£ 210,000$ (for approximately 30 patients) for initiation of this treatment during 2000-01. An initial review highlighted discrepancies between the DAS28 (ie consensus guidelines), and our individual clinical assessment of patients.
Objectives To evaluate prospectively a cohort of consecutive eligible patients, prioritise them according to a weighted scoring system, which we developed and observe changes in the profile of those fulfilling these revised criteria for treatment.

Methods In a 3 month period, potential patients were recruited to an assessment clinic. Those fulfilling the criteria were further stratified using a 5-point cumulative scoring system based on 4 variables: 1) DAS28, 2) Age, 3) Disease duration and 4) Steroid dose. This weighted towards younger patients with shorter disease duration, requiring steroids and having a high DAS28, on the assumption that treating such patients would be more costeffective. This resulted on a final list of 30 patients selected for treatment (N/N Priority).

Results 135 out of 139 patients assessed, fulfilled the BSR eligibility criteria. Nearly two thirds of the 30 patients with the highest DAS28 (BSR priority) were subsequently replaced on our stratified list (N/N Priority). However, funding is still not available for $78 \%$ of our patients, who are otherwise eligible for treatment.

\begin{tabular}{lllll}
\multicolumn{4}{l}{ Abstract FRI0056 Table 1} \\
\hline Variables & N & $\begin{array}{l}\text { DAS28 } \\
\text { (Range) }\end{array}$ & $\begin{array}{l}\text { Age } \\
\text { (Years) }\end{array}$ & Duration \\
\hline TOTAL & 135 & $7.06(5.1-8.9)$ & $57(17-82)$ & $14(0.6-55)$ \\
BSR PRIORITY & 30 & $8.16(7.69-8.9)$ & $59(30-82)$ & $14(1-35)$ \\
N/N PRIORITY & 30 & $7.57(5.1-8.9)$ & $46(17-78)$ & $8.1(0.6-20)$ \\
\hline
\end{tabular}

Conclusion Rationing creates difficult choices. We have attempted to select patients according to need and cost effectiveness. These decisions should be debated openly as they have important implications for health policy and clinical management.

\section{REFERENCES}

1 British Society for Rheumatology - Report of a Working Party, April 2000

2 Updated consensus statement on TNF blocking drugs for the treatment of RA. Ann Rheum Dis. 2000;59(Suppl I):i1-i2

\section{FRI0057 EFFECTS OF CYCLOSPORINE/METHOTREXATE COMBINATION THERAPY FOLLOWED BY SINGLE AGENT TREATMENT ON RADIOGRAPHIC PROGRESSION IN EARLY RHEUMATOID ARTHRITIS}

A Marchesoni, N Battafarano, M Arreghini, M Cagnoli, P Prudente, R Pellerito, S Tosi. Rheumatology, G. Pini Orthopaedic Institute, Milan, Italy

\subsection{6/annrheumdis-2001.1186}

Background Early treatment of severe rheumatoid arthritis (RA) with cyclosporine (CsA) and methotrexate (MTX) in combination is now considered one of the best strategies to control the arthritic symptoms and prevent structural joint deterioration.

Objectives This trial was aimed at evaluating the clinical and radiographic outcome of a cohort of patients with early rheumatoid arthritis (RA) first treated with an association of CsA and MTX, and then randomly stepped down to one of two agents. Methods Fifty-seven patients (54 F and $3 \mathrm{M}$ ) (mean age 49.5 yr., range 20-64) with early, active RA (mean disease duration 0.8 yr., range $0.5-2)$, were treated with CsA $(3 \mathrm{mg} / \mathrm{kg} /$ day $)$ and MTX (10-15 mg/week) in combination for 6 months and then 49 of them were randomised to receive single therapy with either CsA (22 patients) or MTX (27 patients) for another 18 